\title{
O contextualismo semântico na filosofia da linguagem de François Recanati
}

\section{Semantic contextualism in François Recanati's philosophy of language}

Giuseppe Varaschin ${ }^{1}$

Mestrando em Linguística pelo Programa de Pós-Graduação em Linguística da (UFSC) e bolsista do CNPq.

E-mail: giuseppe.varaschin@gmail.com
RESUMO: 0 objetivo deste artigo é apresentar aos linguistas a discussão filosófica acerca do papel do contexto na teoria semântica. Os contextualistas alegam que certas informações contextuais não-demandadas pelas regras estritamente linguísticas precisam se fazer presentes na significação que atribuímos aos enunciados. Um autor que desenvolveu argumentos persuasivos em prol dessa posição foi o filósofo francês François Recanati. Apresentaremos aqui alguns de seus argumentos e algumas das consequências que suas hipóteses, a serem exatas, acarretam para a teoria linguística. Concluiremos com algumas breves considerações acerca de como os linguistas devem participar desse debate originário da filosofia. Palavras-chave: Filosofia da Linguagem; Contextualismo; François Recanati; Semântica

ABSTRACT: This article's objective is to present to the linguists the philosophical discussion about the role of context in semantic theory. Contextualists claim that certain contextual information that is not demanded by strictly linguistic rules must be present in the meaning we attribute to utterances. An author who has developed persuasive arguments in favor of this position is the French philosopher François Recanati. We will present here some of his arguments and some of the consequences that his hypotheses, if they are exact, imply for linguistic theory. We will conclude with some brief remarks regarding the way linguists should partake on this philosophically originated debate.

KEYwoRDs: Philosophy of Language; Contextualism; François Recanati; Semantics. 


\section{Introdução}

$\mathrm{M}$ uitos dos programas de pesquisa em vigência na linguística foram motivados por reflexões provenientes de outras áreas. A filosofia, em especial, pode assumir a paternidade por várias das ideias que estão na base da prática científica do linguista. O programa gerativista está assentado sobre fundamentos racionalistas, a semântica formal justifica-se com argumentos davidsonianos, o cognitivismo busca suas raízes no segundo Wittgenstein. Isso para não falar da pragmática, área cujo cânone (os clássicos sobre teoria dos atos de fala, teoria das implicaturas e dêixis) é ainda de autoria quase exclusiva de filósofos de profissão. Uma discussão florescente na filosofia da linguagem de vertente analítica atual se preocupa em delimitar o papel exato do contexto na determinação das condições de verdade ou das proposições. Alguns autores - os contextualistas - buscam enfatizar esse papel, enquanto outros - os minimalistas - buscam minimizá-lo. É conveniente que os linguistas tomem consciência dessa discussão, pois, em última instância, o que vai decidi-la são conclusões empíricas acerca da análise da estrutura e do processamento da linguagem. O objetivo deste artigo é trazer esse debate para mais próximo do universo dos linguistas.

Há muitas formas de apresentar a discussão em torno do contextualismo - quase tantas quanto há posições a assumir. Cada pesquisador parece categorizar seus oponentes e formular a disputa em seus próprios termos, de acordo com seus próprios interesses de pesquisa. Como fator agravante, existe ainda uma vertente de autores (chamados, por Recanati (2004), de sincretistas) que desconsideram que o debate tenha, em si, qualquer substancialidade, pois as supostas alternativas conflitantes seriam, ou apenas variantes notacionais que não acarretam nenhuma diferença empírica, ou teorias diferentes a respeito de coisas diferentes (cf. BEZUIDENHOUT, 2009). $\mathrm{O}$ autor de que trataremos aqui - o filósofo e cientista cognitivo francês
François Recanati - foi tanto alguém que propôs uma teoria própria - em Recanati (2010) - quanto alguém que mapeou o terreno de teorias possíveis - em Recanati (2004). Por essas razões, seu estudo acaba se configurando como um ponto de vista privilegiado para entrar no debate acerca do papel do contexto na semântica.

\section{Uma definição de contextualismo}

Antes de mergulharmos nos argumentos contextualistas de Recanati, é prudente que tenhamos à mão uma definição relativamente segura do contextualismo, para que saibamos exatamente em favor do quê os filósofos estão argumentando.

O contextualismo pode ser definido a partir da rejeição de um pressuposto muito difundido entre os semanticistas. Esse é um pressuposto a respeito do funcionamento da composição semântica. Recanati chama esse pressuposto de "suposição fregeana" (SF) e o caracteriza da seguinte maneira:

SF: O que uma expressão contribui - quando ela é empregada (juntamente com outras expressões) na realização de um enunciado completo - ao sentido do enunciado é o sentido que ela possui independentemente em virtude das convenções linguísticas (2010, p. 17).

Há, a meu ver, quatro motivos para rejeitar SF (apenas dois deles são mencionados por Recanati (2010)). Cada um desses motivos assinala uma modalidade peculiar de contextualismo. Passemos, de um a um, por todos eles, indo dos mais fracos aos mais fortes - em uma ordem em que cada um é acarretado pelo que o segue:

(i) Podemos gerar a contraditória de SF, transformando-a em uma proposição existencial negativa: o que uma expressão contribui ao sentido do 
enunciado (às condições de verdade, à proposição) não precisa ser sempre o seu sentido lexicalizado (aquele que ela possui "independentemente em virtude das convenções linguísticas”). Isso não implica dizer que os sentidos que as expressões contribuem nunca são os sentidos lexicalizados, nem que geralmente não o são. Para validar (i), basta que apresentemos um único caso em que a expressão não contribui seu sentido lexicalizado às condições de verdade. Nesse sentido, a modalidade de contextualismo implicada por (i) - que Recanati $(2004$, p. 137) chama de "visão da opcionalidade forte" - é a mais modesta de todas. É essa a abordagem que Recanati (2010) adota na sua pragmática verocondicional.

(ii) Podemos gerar a contrária de SF, transformando-a em uma proposição universal negativa: o que uma expressão contribui ao sentido do enunciado (às condições de verdade, à proposição) nunca é o seu sentido lexicalizado (aquele que ela possui "independentemente em virtude das convenções linguísticas). O contextualismo que decorre de (ii) é, grosso modo, o que Recanati (2004, p. 138-140) apelida de "visão da composição pragmática”. De acordo com essa visão, é a composicionalidade que força o ajuste pragmático do sentido lexicalizado das expressões. Essa visão se aproxima de algumas considerações de Pustejovsky (1995) sobre a coerção semântica e o processo de cocomposição.

(iii) Podemos negar uma das pressuposições de SF, a saber, a ideia de que as convenções linguísticas associam sentidos às expressões da língua. A rejeição implicada em (iii) sugere, portanto, que os itens lexicais simplesmente não codificam sentidos, isto é, constituintes proposicionais. Em outras palavras: "o significado das palavras e/ou sentenças [...] não é suficiente para garantir sequer uma proposição mínima." (RECANATI, 2004, p. 97) O significado puramente linguístico deve ser, de acordo com essa visão, radicalmente divorciado da referência e das condições de verdade. É seguindo esse espírito que os Teóricos da Relevância, como Carston (1991) e Sperber e Wilson (1995), insistem em manter distintas a semântica linguística (a semântica das sentenças das línguas naturais) e a semântica verocondicional (a semântica das representações conceituais). Vale antecipar que uma grande dose de confusão pode ser evitada se diferenciarmos essas duas formas de semântica. A primeira estabelece regras de correspondência entre itens sintáticos e entidades mentais (conceitos), e a segunda estabelece relações entre entidades mentais (conceitos) pragmaticamente enriquecidos e o mundo. É esse tipo de postura que Recanati (2004, p. 140) chama de "visão do formato inadequado", pois nela é como se os significados estritamente linguísticos tivessem um formato inadequado para contribuírem com a proposição.

(iv) Por fim, podemos negar outra pressuposição de SF: a ideia de que os próprios enunciados veiculam sentidos, condições de verdade ou proposições determinadas. Essa é, conforme já mencionei, a postura que Borg atribui a Travis, visto que segundo ela, o filósofo inglês nega que "um sentido determinado possa ser recuperado de um determinado ato linguístico" (BORG, 2004, p. 221). O contextualismo que parte de (iv) não diz simplesmente que o significado lexicalizado das expressões não é suficiente para determinar o seu sentido - isto é, a contribuição que elas dão às proposições em que aparecem -, mas sim que não existem propriamente sentidos e proposições. Além da posição wittgensteiniana radical capitaneada por Travis, outra abordagem que se enquadra nessa categoria é o behaviorismo semântico de inflexão quineana (v. MOURA e VARASCHIN, 2013). Essa postura implica um ceticismo generalizado a respeito de todos os tipos de representação. Apelidarei esta alternativa de visão da eliminação do sentido. 
A visão positiva acerca da composição semântica que caracteriza o contextualismo acaba sendo, a meu ver, aquela que Jackendoff (1997) chama de composicionalidade enriquecida:

A estrutura conceitual de uma sentença pode conter, além do conteúdo conceitual dos itens lexicais, outros materiais que não estão expressos lexicalmente, mas que precisam estar presentes na estrutura conceitual para (...) satisfazer aspectos pragmáticos do discurso ou do contexto extralinguístico (p. 49).

Adotar o contextualismo acarretaria, portanto, abandonar uma visão segundo a qual a composição semântica é sintaticamente transparente, isto é, segundo a qual "todos os elementos de conteúdo no significado de uma sentença podem ser encontrados na estrutura conceitual lexical dos itens lexicais que compõem a sentença" (ibidem, p. 48). A composição semântica deixaria de ser, assim, totalmente guiada pela estrutura sintática, pois não seria mais apenas o resultado da aplicação mecânica de regras de correspondência entre o nível sintático e o nível semântico. Outros fatores teriam que ser considerados para entendermos o modo como os conceitos lexicais são combinados para formar conceitos sentenciais complexos.

\section{Recanati e a acessibilidade do que é dito}

O ponto de partida das reflexões próprias de Recanati, desde seus primeiros artigos sobre o tema, é o conceito de o que édito, tal qual formulado, de uma maneira desconcertantemente sintética, por Paul Grice (1989). Grice assevera que a "significação total de um enunciado" pode ser dividida de duas maneiras: primeiro, entre aquilo que é dito, no "sentido favorecido", e aquilo que é implicado, e, em seguida, entre aqueles aspectos que fazem parte da "força convencional" (ou que estão linguisticamente codificados) e aqueles que não fazem. Em seu texto, Grice faz referência a um "sentido favorecido" do termo "o que é dito", sugerindo, assim, que a expressão não está sendo empregada de maneira informal, mas remete a um uso técnico, interno ao próprio projeto griceano. Se examinarmos o influente Logic and Conversation, registro escrito das William James Lectures, proferidas por Grice em 1967, vemos a que se reporta tal sugestão:

No sentido em que estou usando a palavra dizer, o que alguém disse está intimamente relacionado ao significado convencional das palavras (da sentença) que está usando. Suponha que alguém tenha usado a sentença 'He is in the grip of a vice' ('Ele está sob o poder de um vício' ou 'Ele está preso pelo torno'). Dado o conhecimento de língua inglesa, mas nenhum conhecimento das circunstâncias da enunciação, sabe-se alguma coisa sobre o que o falante disse, admitindo-se que ele estava falando inglês, e falando literalmente. Sabese que ele disse, a respeito de alguma pessoa do sexo masculino ou de algum animal $X$ que, ao tempo da enunciação (qualquer que tenha sido este tempo) uma ou outra coisa: 1) ou X era incapaz de livrar-se de algum traço de mau caráter; 2) ou que alguma parte de X estava presa a um certo tipo de ferramenta ou instrumento [...]. Para uma identificação completa do que o falante disse necessitar-se-ia saber (a) a identidade de X; (b) o tempo da enunciação; e (c) o significado, na ocasião particular da enunciação, da sequência 'in the grip of a vice' [uma decisão entre (1) e (2)] (GRICE, 1989, p. 25).

Assim, a noção de "o que é dito", contrasta, de um lado, com o significado literal convencionalmente associado às expressões, e, de outro, com as implicaturas conversacionais calculadas inferencialmente a partir do que é dito e da suposição que o falante está sendo cooperativo. Há, então, a princípio, três camadas de significação possíveis para uma sentença: (1) o significado convencionalmente associado à sentença pelas regras semânticas da língua; (2) o que é dito por essa sentença em um dado contexto; e, (3) o que o falante quer comunicar, usando essa sentença nesse contexto, a um interlocutor cooperativo.

A questão que imediatamente se levanta, para Recanati, é a de saber com precisão, para retomar a qualificação de Grice, o quão intimamente 
(1) está relacionado com (2). A maneira tradicional de compreender essa qualificação é a de tomá-la no sentido mais forte possível, seguindo dois princípios muito adotados (amiúde tacitamente) pelos semanticistas. O primeiro, que reflete uma mentalidade mais filosófica, é o que Recanati (1991; 2004) chama de princípio minimalista: "o que é dito vai além do significado convencional da sentença (e incorpora elementos contextuais) apenas quando isso é necessário para 'completar' o significado da sentença e torná-lo proposicional” (RECANATI, 2004, p. 7). ${ }^{1}$ O segundo, refletindo um ponto de vista mais linguístico, é rotulado por Robyn Carston de princípio do direcionamento linguístico: "um aspecto pragmático da significação é parte do que é dito se e somente se sua determinação contextual é acionada pela gramática, isto é, se a própria sentença exibir uma lacuna que deva ser contextualmente preenchida" (CARSTON, 2014, p. 16). Recanati (2004) chama, indistintamente ${ }^{2}$, os propugnadores (em sua maioria não-declarados) desses princípios de minimalistas. A expressão se justifica porque a postura

\footnotetext{
Além de descrever as relações permitidas entre (1) e (2), o princípio minimalista é também adotado implicitamente como critério para discriminar os aspectos contextualmente determinados da significação que são partes de (2) daqueles que são partes de (3). É como um critério para traçar a fronteira entre o que é dito e as implicaturas que Recanati (1991) discute e formula o princípio minimalista. De acordo com essa aplicação, toda influência pragmática na significação que não for necessária para a proposicionalidade será uma implicatura. Os critérios explicitamente reconhecidos por Grice - calculabilidade, cancelabilidade, universalidade, etc. - servem para identificar quaisquer aspectos pragmáticos ou contextuais da significação (cf. RECANATI, 1991), e, por isso, só servem de guia para delimitar especificamente as implicaturas se supusermos, além disso, que as implicaturas são os únicos aspectos pragmáticos que afetam a significação (cf. CARSTON, 1991)

2 Carston (2002), na sua discussão desses dois princípios, defende que ambos produzem resultados e predições coincidentes, com exceção dos casos em que temos fragmentos sentenciais como "A Maria comeu" ou "O João está pronto". Nessas ocorrências, o princípio do direcionamento linguístico não exigiria nenhum tipo de complementação contextual, ao passo que o princípio minimalista o exigiria, pois o resultado do processamento linguístico dessas sentenças seria meramente fragmentário, e não uma proposição completa. No entanto, segundo Recanati (2002), as informações adicionais requeridas para tornar esses fragmentos plenamente proposicionais podem ser recuperadas a partir das entradas lexicais das palavras "comer" e "pronto". No primeiro caso, por exemplo, temos um verbo transitivo, lem cuja entrada lexical há a informaç̃o de que ele exige a presenç de dois argum verbo transitivo, cmaver nada na a "come " fato de não haver nanto interno não nos deve sugerir que a provisão contextul dorse que "conto não sejana um
}

que a define determina que a distância entre (1) e (2) é a mínima possível, e que, portanto, as proposições expressas pelos enunciados são proposições mínimas. Nos termos da semântica verocondicional, o minimalismo acarreta que as condições de verdade de um enunciado são, igualmente, condições de verdade mínimas, ou aquilo que Borg (2004) chama de condições de verdade liberais.

\section{A saturação}

É crucial perceber que os minimalistas não contestam a alegação de que as contribuições do contexto são necessárias, ao menos ocasionalmente, para completar os significados das sentenças e torná-los plenamente proposicionais. Eles não são anticontextualistas nesse sentido, afinal de contas, segundo eles, a proposição pode incorporar elementos contextuais - ainda que ela só possa incorporá-los quando ela tiver que os incorporar para se tornar uma proposição completa. Nem mesmo os minimalistas mais estridentes ${ }^{3}$ negam que, por exemplo, a sentença "Eu sou francês" expresse proposições diferentes em contextos diferentes - algumas das quais serão verdadeiras e outras falsas -, e que essa variação não seja um caso de ambiguidade, mas sim de interferência do contexto nas condições de verdade - nesse caso específico, na atribuição de referência a um dêitico. Isto é, eles concordam que o significado da sentença é, em geral, uma espécie de "esqueleto semântico", que precisa ser consubstanciado a algum fator

3 "A proposição mínima não pode ser caracterizada de um modo completamente independente do contexto de enunciação. O minimalismo semântico reconhece que há um pequeno conjunto de
expressões que interagem com os contextos de enunciação de maneiras privilegiadas. Chamamos essas expressões de expressões genuinamente sensíveis ao contexto" (CAPPELEN; LEPORE, 2005, p. 143) Vale observar, no entanto, que os minimalistas procuram reduzir a influência contextual ao mínimo possível, restringino à̀ "esgotam a dimensão da influência contextual no conteúdo semântico" (ibidunto de expressões" qu esgotam a dimensão da influência contextual no conteúdo semântico" (ibidem, p. 143). Em outras
palavras, toda dependência contextual seria uma instância de dêixis. 
contextual para resultar em uma proposição completa com condições de verdade definidas. Entretanto, a única contribuição do contexto que eles admitem é aquela que Recanati $(1991 ; 2004 ; 2010)$ caracteriza como saturação:

A saturação é o processo pelo qual o significado da sentença é completado e tornado proposicional através da atribuição contextual de valores semânticos aos constituintes da sentença cujas interpretações são dependentes de contexto (e, possivelmente, através do suprimento contextual de constituintes proposicionais 'inarticulados', se presumirmos, como fazem alguns filósofos, que tais constituintes são às vezes necessários para tornar uma sentença plenamente proposicional). Esse processo ocorre sempre que o significado da sentença incluir algo como uma 'lacuna' que precise ser completada, ou uma 'variável livre' que requeira uma instanciação contextual. [...] A saturação só ocorre quando o apelo ao contexto é necessário para que o enunciado expresse uma proposição completa. De um ponto de vista semântico, a saturação é um processo contextual obrigatório (RECANATI, 2004, p. 7).

Recanati elenca como exemplos inequívocos de saturação a atribuição de referentes às expressões indexicais, a especificação de relações para genitivos e compostos nominais como "o livro de João" ("John's book") e "pesadelo de ladrões" ("burglar's nightmare"), a identificação de classes de comparação para os predicados paramétricos (p. ex., a especificação "para uma criança" em sentenças como "João é alto") e o fornecimento de argumentos não enunciados (mas exigidos pela estrutura argumental) nos casos de instanciação nula definida (p. ex., como a provisão contextual do complementizador "o bolo" à interpretação de um proferimento como "João viu"). O que os minimalistas sustentam é que todos os ajustes pragmáticos de sentido que não se enquadrarem nesse modelo - isto é, que não forem absolutamente necessários para a expressão de uma proposição - não fazem parte do que é dito. Nos termos usados por Recanati, isso quer dizer que o único processo pragmático primário (i.e., processo anterior à identificação da proposição) para eles é a saturação. Todos os aspectos da significação que não forem indispensáveis para que uma dada representação seja uma proposição (tenha condições de verdade, possa ser avaliada em termos de verdade ou falsidade, etc.) não fazem parte do que é dito. Se adotarmos, adicionalmente, a divisão tripartida dos níveis de significação sugerida por Grice (1989), concluiremos que qualquer processo pragmático opcional deve ser relegado ao âmbito das implicaturas. ${ }^{4}$

\section{Previsões extravagantes}

Recanati $(1991 ; 2004 ; 2010)$ principia sua argumentação contra o minimalismo observando que as proposições mínimas não são, ao menos em algumas ocasiões, as proposições que, intuitivamente, pensamos expressar

${ }^{4}$ É plausível supor que essa maneira de compreender a relação entre as camadas de significação seja um legado do próprio Grice. No tre a lece a lribuiç̃o indexicais, como a indicaç̃o de tompo nos verbos; $\mathrm{e}$ por fim, (3) a resoluç̃o de ambiguidades lexsóes indexicais, como a indicação de tempo nos verbos; e, por fim, (3), a resolução de ambiguidades lexicais e estruturais. Se presumirmos que Grice, ao expor esse seu argumento, está sendo cooperativo, e que, em especial, está agindo de acordo com a máxima da quantidade tal qual formulada por ele, derivaremos, do fato de que ele mencionou apenas três subtarefas, a implicatura de que há apenas essas três subtarefas. Ora, com exceção de (3), os processos citados por Grice são, indiscutivelmente, exemplos de saturação. Na verdade, mesmo a resolução de ambiguidades pode ser pensada como um processo pragmático primário obrigatório, haja vista que, sem ela, não chegaríamos a uma (única) representação proposicional. A constatação de que fatores contextuais robustos afetam a desambiguação não é, de modo algum, incompatível com o minimalismo modularista: "O apelo a fatores que vão além as propriedades puramente formais da cadeia tomada como input pode ser pensado aqui como ocorrendo antes do processamento linguístico propriamente dito. Isto é, embora talvez precisemos recorrer outros domínios do conhecimento, além do puramente linguístico, para determinar precisamente qual é o input linguístico, esse recurso inicial não parece ser contraditório com o fato de que, uma vez que o input linguístico foi determinado, então ele pode ser processado semanticamente, sem recorrer informações extralinguísticas." (BORG, 2004, p. 141). Assim, os processos centrais da inteligência já forneceriam ao módulo linguístico um input desambiguado para ser processado segundo diretrizes minimalistas (isto é, sem recorrer a informações contextuais exceto quando estas forem necessárias para atingir o nível proposicional mínimo). Borg (2004) propõe ainda outra alternativa: é possível que se os mecanismos da inteliô̂n minino ). Borg (2004) propõe ainda outrá alternativa: é possivel que se os mecanismos da inteligência geral não filtrarem a ambiguidade, o módulo linguístico aceite um input ambíguo e devolva à inteligência geral para a interpretação (e seleção) pragmática duas (ou mais) proposições mínimas semanticamente interpretadas. Ou seja, no caso da desambiguação, os processo centrais sensiveis ao contexto podem operar antes ou depois da interpretação semântica, sem que
precisem se misturar com ela. 
com nossos enunciados. Em outras palavras: as proposições mínimas não são, muitas vezes, proposições que estão acessíveis à nossa consciência durante boa parte das nossas interações verbais. Consideremos os seguintes exemplos adaptados de Recanati (2004) e Carston (1991):

(1) Eu já tomei café da manhã.

(2) Você não vai morrer.

(3) A mesa está coberta de livros.

(4) Maria deu a chave para João e ele abriu a porta.

Para todas essas sentenças, o princípio minimalista acarreta que o que é literalmente dito não é o que é intuitivamente dito. A primeira proposição, por exemplo, seria literalmente verdadeira mesmo em um caso em que o falante tomou café da manhã uma única vez, 50 anos antes de proferir a sentença que a expressa. A rigor, essa proposição tem a mesma estrutura semântica que o famoso exemplo de Sperber e Wilson (1995, p. 189):

(5) Eu já fui ao Tibete.

Isso porque as proposições mínimas de (1) e (5) dizem apenas que o falante $\mathrm{S}$ tomou café da manhã, ou foi ao Tibete, em algum momento $\mathrm{t}^{*}$ anterior a t, sendo to instante de proferimento do enunciado. A delimitação temporal complementar que ocorre em (1) - e que, em geral, não ocorre em (5) - isto é, a ideia de que o falante tomou café da manhã no mesmo dia da enunciação, deve, segundo o princípio minimalista, ser tida como algo externo ao que é dito, visto que uma proposição completa pode ser expressa sem essa sugestão; assim seria também de acordo com o princípio do direcionamento linguístico, haja vista que nada nessa sentença nos obriga a inserir na proposição a referência implícita ao dia da enunciação.
Portanto, essa referência deve ser tida como uma implicatura conversacional calculada a partir de uma aparente violação das máximas da relevância e da quantidade.

Já em (2) temos um caso em que, segundo o princípio minimalista, o que dizemos não é simplesmente diferente do que intuitivamente pensamos dizer, mas é algo que não diríamos de modo algum, visto ser algo patentemente falso. Bach (1994), de quem Recanati extrai esse exemplo, imagina um contexto em que uma mãe profere (2) para acalmar seu filho, que chora por causa de um corte no dedo. 0 que a mãe pretende dizer seria, então

(2*) Você não vai morrer por causa desse corte.

Mas a proposição literalmente expressa por essa mãe seria a de que seu filho não vai morrer tout court, isto é, a de que ele é uma espécie de ser imortal. A mãe estaria, então, segundo os minimalistas, dizendo algo literalmente (e obviamente) falso para o seu filho. A referência implícita ao corte não corresponde a nada na estrutura da sentença, e não é, tampouco, necessária para torná-la plenamente proposicional. Logo, essa referência deve, novamente, ser uma instância de implicatura conversacional, nesse caso, uma implicatura gerada a partir de uma exploração da máxima da qualidade.

O exemplo (3) é um caso que contém aquilo que Soames (1986) chama de descrição definida incompleta. A descrição definida "a mesa" é incompleta porque ela, por si só, não é suficiente para identificar um objeto único no mundo, já que a extensão do predicado "mesa" (que é o único predicado dessa descrição), no nosso modelo de mundo, é um conjunto não-unitário. Ocorre, porém, que, segundo Russell (1905), as condições de verdade das descrições definidas contêm uma afirmação de unicidade. As condições de verdade do enunciado (3) poderiam ser formuladas, usando o cálculo de 
predicados de primeira ordem como metalinguagem, da seguinte maneira (sendo $\mathrm{I}(\mathrm{M})$ = $\mathrm{x}$ é uma mesa e $\mathrm{I}(\mathrm{L})=\mathrm{x}$ está coberta de livros):

$\left(3^{*}\right) \exists x[(M x \wedge \forall y(M y \rightarrow x=y)) \wedge L x]$

Ou seja, alguém que diz "A mesa está coberta de livros" está, segundo o minimalista, dizendo, literalmente, que existe uma única mesa no universo, e que essa mesa está cheia de livros. De novo, temos aqui um caso em que a proposição prevista pelo princípio minimalista e pelo princípio do direcionamento linguístico não corresponde à proposição que está acessível à nossa consciência, já que aquela, ao contrário desta, é claramente falsa. ${ }^{5}$ Dado que nem a restrição do domínio do quantificador existencial para incluir apenas os objetos de uma determinada sala e nem a expansão do predicado "mesa" em algo como o conceito ad hoc MESA-DA-SALA-515DO-BLOCO-B-DO-CCE-NA-UFSC são necessárias para que (3) expresse uma proposição mínima completa - a saber, $\left(3^{*}\right)$-, devemos considerar essas possíveis suplementações do significado literal como posteriores ao cálculo das condições de verdade, ou seja, como implicaturas.

Já (4) é semelhante a um exemplo discutido pelo próprio Grice (1981) a partir de algumas considerações de Strawson (2011). Intuitivamente, pensamos que (4) expressa uma proposição como

$\left(4^{*}\right)$ Maria deu a chave para João e $[\text { depois }]_{{ }^{\prime}}[\text { João }]_{\mathrm{b}}$ abriu a porta $[\text { com a chave }]_{c^{*}}$

5 É necessário, contudo, fazer justiça aos minimalistas e dizer que nem todos aceitam ( $3^{*}$ ) como as condições de verdade literais da sentença (3). Stanley e Szabo (2000) sustentam que, na forma lógica de (3), há uma variável para um domínio de entidades que precisa ser preenchida para que (3) expresse uma proposição completa. Essa variável não precisa receber o mundo inteiro como domínio - até porque é extremamente difícil dizer o que é o conjunto de entidades do mundo sem recorrer a uma espécie de "conjunto universal", ideia que conduz a contradições insuperáveis (cf. MORTARI, 2001). A restrição do domínio do quantificador seria, então, segundo esses autores, um exemplo de saturação (cf. RECANATI, 2004). De acordo com Recanati (1991), se considerarmos que (1) e (2) envolvem quantificação sobre eventos, uma análise semelhante é possível - o que não significa que seja desejável quantificação sobres exemplos também.
Com exceção da atribuição de referência ao pronome anafórico "ele", que é uma ocorrência de saturação, nenhum dos enriquecimentos proposicionais marcados acima entre colchetes são consistentes com o princípio minimalista (ou com o princípio do direcionamento linguístico). Tanto a leitura temporal da conjunção "e" quanto a especificação do instrumento em (c) teriam, então, que ser consideradas como implicaturas conversacionais. Na verdade, a descrição do acréscimo temporal de (a) como uma implicatura conversacional generalizada projetada a partir da obediência à quarta submáxima do modo - "seja ordenado" (GRICE, 1989, p. 27 - foi a proposta original de Grice (1981) diante dos problemas levantados por Strawson (2011).

A afirmação de que as proposições construídas a partir do princípio minimalista e do princípio do direcionamento linguístico são diferentes daquelas que, intuitivamente, pensamos expressar não é ainda uma objeção. Essas considerações só afetam a credibilidade do minimalismo se supusermos, adicionalmente, que temos algum motivo para respeitar nossas intuições de falantes. Devemos perceber, no entanto, que isso não é uma exigência comum para uma teoria científica. Os físicos não têm de prestar satisfações à nossa teoria intuitiva sobre como o mundo funciona; semelhantemente, os psicólogos que estudam as emoções humanas não precisam dar uma resposta a todas as inquietações presentes nos manuais de autoajuda. Há, em suma, uma visão amplamente aceita da relação entre o conhecimento científico e o senso-comum, chamada por Recanati de "visão anti-preconceito", que prescreve que "não há nada de sacrossanto nos nossos conceitos ordinários de senso comum. Se uma consideração teórica for consistente com nossas intuições de senso comum, melhor, se não for, pior para o senso comum" (RECANATI, 1991, p. 115).

Foi pela força do prestígio desse lugar-comum epistemológico que os minimalistas puderam ampliar o domínio das implicaturas (para incluir, por exemplo, a noção de sequenciação temporal em (4)) sem que ninguém 
protestasse. Existem, porém, diferenças fundamentais entre os aspectos da significação não-articulados dos exemplos (1)-(4) e os casos mais claros e incontroversos de implicaturas:

(5) Eu sou brasileiro.

(5*) É óbvio que sei jogar futebol.

Suponhamos que (5) seja proferida por mim em resposta à pergunta "Você sabe jogar futebol?". A partir disso, o ouvinte está autorizado, pelas máximas da conversação e pelo seu conhecimento de como as habilidades futebolísticas estão distribuídas entre os habitantes das várias regiões do mundo, a inferir que o que quis comunicar foi algo como a proposição ( $\left.5^{*}\right)$. A acessabilidade à nossa intuição é, precisamente, uma das diferenças entre (1)-(4) e esse novo exemplo (5):

No último exemplo, a implicatura é intuitivamente percebida como externa ao que é dito; ela corresponde a algo que normalmente tomaríamos como tendo sido 'implicado'. No[s] caso[s] anterior[es], não somos capazes de distinguir, pré-teoreticamente, entre os dois supostos componentes da significação dos enunciados (RECANATI, 1991, p. 115).

Essa diferença, segundo Recanati, deveria incitar as seguintes questões: estamos tratando de uma mesma coisa nos dois casos? E, se estamos, "como podemos explicar essa diferença?" (p. 115). Ou seja, dada a sua propensão a tratar certos aspectos da significação intuitiva de (1)-(4) como implicaturas conversacionais externas ao que é literalmente dito, "o minimalista precisa explicar por que essas implicaturas, ao contrário dos casos prototípicos [como (5)], não apresentam a propriedade da 'acessabilidade' à consciência” (RECANATI, 2004, p. 12). Isso porque, no campo da cognição humana, nossas intuições não são apenas um primeiro passo rumo à teorização - algo como a escada de Wittgenstein, que pode ser descartada uma vez que tenha sido usada para alcançar um patamar superior - mas sim parte do assunto da teorização, e, enquanto tais, não podem ser negligenciadas (RECANATI, 1991, p. 115)

O minimalista precisa, se seu objetivo for construir uma teoria psicologicamente realista da compreensão verbal, explicar por que a derivação de algumas implicaturas é acessível à consciência e a de outras não, ou, em outras palavras, por que é em apenas alguns casos que a distinção entre o que é dito e o que é implicado corresponde fielmente às nossas intuições.

Recanati (2004) reconhece como o único esforço nessa direção a distinção griceana entre implicaturas conversacionais generalizadas e particularizadas. ${ }^{6}$ Aquelas, ao contrário destas, "são difíceis de distinguir do conteúdo semântico das expressões linguísticas, porque tais implicaturas [estão] rotineiramente associadas a expressões linguísticas em todos os contextos normais" (LEVINSON, 1983, p. 127). O minimalista poderia alegar que os enriquecimentos em (1)-(4) são, precisamente, exemplos de implicaturas generalizadas, e que tais implicaturas são "geradas e interpretadas de modo inconsciente e automático" (RECANATI, 2004, p. 12).

Mesmo supondo que a classe das implicaturas conversacionais generalizadas seja passível de ser caracterizada pela geração inconsciente e automática de seus membros, ${ }^{7}$ (motivo pelo qual, supostamente, nossas

${ }^{6}$ Recanati (1991, p. 118) cita também a noção de "não-literalidade padronizada", que cumpriria no quadro adotado por Bach (1987), um papel semelhante ao das implicaturas conversacionais generalizadas para os neogriceanos. As sentenças (1)-(4) estariam, de acordo com o filósofo americano, padronizadamente associadas aos enriquecimentos que citamos, e, por conta dessa espécie de "forç do hábito", nós nem notaríamos mais que tais acréscimos não fazem parte do que é dito. Haveria, nesse sentido, uma semelhança entre (1)-(4) e os casos de atos de fala indiretos padrozinados.

7 O que não é de modo algum evidente, haja vista que, segundo Horn, "a natureza generalizada de uma implicatura não acarreta sua inacessibilidade à consciência - seu caráter críptico. É possível que uma implicatura seja a mesmo tempo, generalizada e intuitivamente acessível como uma implicatura

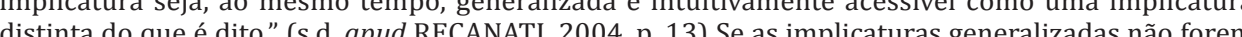
distifor do que é dito" (s. apud RECAN a diferença entre casos como (1)-(4) e (5) volta a carecer de explicação. 
intuições a seu respeito seriam "embaralhadas"), há outros problemas em considerar os ajustes de sentido dos exemplos (1)-(4) como implicaturas. 0 primeiro é que a presunção de que essas supostas implicaturas sejam calculadas de modo inconsciente com base em um conteúdo dito também inacessível à intuição dos falantes nos afasta muito do panorama teórico delineado por Grice. O segundo é que essas informações não-obrigatórias que extraímos da enunciação de (1)-(4) acabam fazendo parte da proposição, o que também é contrário à ideia de Grice de que as implicaturas são calculadas com base em uma proposição previamente expressa. Quero deixar claro que abandonar a chamada "raiz Griceana" (RECANATI, 2010), da pragmática pode não ser de todo uma má ideia - e, diante de algumas das aporias já levantadas e outras que se levantarão, chega a ser boa ideia -, mas a abandonar enquanto se continua a usar a terminologia de Grice - sem fazer muito esforço para esclarecer a ressignificação dos seus principais conceitos - é, sem dúvida, um convite à confusão. Especialmente quando os proponentes de tais inversões ocultas nos conceitos de Grice insistem em se qualificar como neogriceanos.

\section{A acessibilidade do que é dito}

Comecemos com o conceito de "o que é dito". Para Grice (1989), o dito era uma variedade do significado não-natural. De acordo com a leitura de Recanati, "uma das características distintivas do significado não-natural, na análise de Grice, é o seu caráter essencialmente manifesto" (2004, p. 13). $\mathrm{Na}$ visão tradicional, um falante que não-naturalmente-significa pretende tornar manifesta para o interlocutor uma intenção reflexiva que envolve dois níveis: (i) a intenção de informar ${ }^{8}$ que $P$, para qualquer proposição $P$; e

\footnotetext{
${ }^{8}$ É necessário ressaltar que o artigo original de Grice, publicado em 1948, não fala de uma intenção de E necessario ressaltar que o artigo original de Grice, publicado em 1948, não fala de uma intenção de
informar que $P$, e sim da intenção de provocar uma crença de que P, para os casos assertivos, e de uma intenção de provocar uma vontade de fazer $\mathrm{P}$, para os imperativos (GRICE, 1989). Esse ponto foi objeto (mais neutra) de intenção informativa, desenvolvida mais detalhadamente por Sperber e Wilson (1995).
}

(ii) a intenção de que (i) seja reconhecida. A noção griceana de significação exige, portanto, o reconhecimento das proposições comunicadas. Destarte, considerar o que é dito como uma instância de significação-não-natural implica dizer que o que é dito precisa ser reconhecido pelos falantes:

A visão de acordo com a qual o "dizer" é uma variedade do significado-nãonatural acarreta que o que é dito (bem como o que é significado em geral, incluindo o que é implicado) precisa ser acessível - precisa estar aberto aos olhos de todos. Isso é assim porque o significado-não-natural é essencialmente uma questão de reconhecer intenções. De acordo com essa visão, o que é dito ao proferir uma sentença depende (e dificilmente pode ser separado) das intenções publicamente reconhecíveis do falante. (RECANATI, 2004, p. 14)

Essa concepção da significação sugere, segundo Recanati, um princípio para delimitar o que é dito: o princípio da acessabilidade. Sua primeira formulação, que enfoca o ponto de vista da construção teórica9 ${ }^{9}$ é a seguinte:

9 Nos seus primeiros incursos contextualistas, como em Recanati (1991), o filósofo francês argumenta que esse princípio é pressuposto até mesmo pelos minimalistas. O princípio minimalista pode ser formulado como um bicondicional: um aspecto contextualmente determinado da significação é parte do que é dito se e somente se sua determinação for necessária para que o enunciado expresse uma proposiçăo completa. Segue-se dessa definição que o princípio minimalista so pode ser aplicado se á souberios, de antemão, se o aspecto contextualmente deterninado é ou năo necessário para a proposicionalidade do enunciado. Recanati extrai disso a seguinte conclusão: "o princípio minimalista, ṕ porte náo podé ser usado pá pode ser usado para esse efeito se uma decisão já tiver sido tomação é parte do que é dito, ele só pode ser usado para esse efeito se una decisão já tiver sido tomada a respeito das variáveis que precisariam ser contextualmente instanciadas para que o enunciado expresse uma proposiçán completa" (191, p. 105). A idela aqui é que mesmo os minimalistas, para dito. Poderíamos elabor r um argumento análo dito. Poderíamos elaborar um argumento análogo para o prinćpio do direcionamento linguístico: ess princípio requer que saibamos, antes da sua aplicação, qualé a estrutura senântica da sentença para, depois, deduzirmos disso a proposicão que a sentença expressa. Mas como poderíamos chegar a essa tal jutura semântica senão pelos dados imediatos e acessiveis do que é dito? Éc somente a partir de um tal julgamento prévio, que parte de um dito disponivel à consciência, que a teorização semântica pode procedicado da antena nálise mais abstrata dos aspectos da signifcação que já estão prescritos no - algo que é postulado para dar conta da base empírica que motiva a construção teórica - algo que é postulado para dar conta da base émpirica que motiva a construçáo térica --, enquanto que o significado do enunciado (o que é dito) é uma hipótese externa, isto é, parte da propria base ser "modificado" " “flexibilizado" conforme as nucrot, implica que é o significado da sentença que pode do enunciado de cuja intuição a feriremos a adequaç̃̃o empírica da teoria. Essa motivação adiciodo do princípio da cuja intuição aferiro sobre a teorização semântica é discutida e rejeitada por Borg (2004). 
"Ao decidir se um aspecto pragmaticamente determinado da significação do enunciado é parte do que é dito, isto é, ao tomar uma decisão a respeito do que é dito, devemos sempre tentar preservar nossas intuições pré-teóricas." (1991, p. 106) A adoção desse princípio não envolve um abandono da celebrada visão anti-preconceito, pois ele se fundamenta em uma hipótese cognitiva peculiar a respeito de como os enunciados são interpretados. Esse viés cognitivista fica mais claro na formulação mais recente do princípio:

Os intérpretes normais têm intuições a respeito do conteúdo verocondicional dos enunciados. Na minha concepção, essas intuições correspondem a um certo "nível" do processo de compreensão - um nível a que uma boa teoria da compreensão linguística precisa prestar satisfação. Esse é o nível do que é dito. [...] Em vez de olharmos as coisas pelo lado linguístico e equacionarmos 'o que é dito' com a proposição mínima a que chegamos pela saturação, podemos adotar uma postura mais psicológica e equacionar o que é dito com (o conteúdo semântico do) produto consciente da série complexa de processamento que subjaz à compreensão. (RECANATI, 2004, p. 16)

Se o que é dito, pela própria natureza da significação, precisa estar acessível à consciência, podemos - e devemos - confiar nas nossas intuições a seu respeito para construirmos uma teoria da compreensão verbal.

Já vimos, entretanto, que o princípio minimalista prevê conteúdos ditos que contrastam com nossas intuições. Isso insere o teórico minimalista em um impasse: ou ele se apega à análise griceana da significação e abandona o minimalismo, ou ele se esquiva do requerimento da acessibilidade (para poder continuar pensando nos ajustes de (1)-(4) como implicaturas) abjurando da análise griceana da significação. A conjunção entre o minimalismo e uma compreensão pragmática do dito é que não pode ser mantida sem incoerência.

Ademais, a alternativa pautada pelo princípio da acessabilidade, ao contrário das abordagens minimalistas, harmoniza-se bem com as observações tradicionais a respeito da derivação das implicaturas. Na teoria de Grice, as implicaturas são concebidas como aspectos pragmáticos da significação inferidos a partir do que é dito e da suposição de que o falante está sendo cooperativo. Recanati argumenta que um aspecto essencial dessa teoria "é o fato de que o ouvinte tem de ser capaz de reconhecer o que é dito e de elaborar a conexão entre o que é dito e o que é implicado ao dizê-lo" (RECANATI, 2004, p. 17). Além de acarretar que o que é dito precisa ser acessível à consciência, essa visão demanda que as implicaturas sejam inferências no sentido estrito, nas quais o falante está consciente tanto do que é dito e do que é implicado, quanto de que há uma conexão inferencial entre ambos (cf. RECANATI, 2010). Contudo, considerar o cálculo das implicaturas como estritamente inferencial não impede que reconheçamos o seu caráter automático, espontâneo e involuntário. Nem toda derivação de implicaturas é explícita - isto é, uma ação voluntária e trabalhosa por parte do ouvinte mas toda derivação de implicaturas é consciente (cf. RECANATI, 2004). Por esse critério também, vemos que aqueles acréscimos de (1)-(4) não podem ser tidos como implicaturas, haja vista que em qualquer um deles os falantes não teriam conhecimento algum de terem computado previamente uma proposição mínima e derivado inferencialmente, a partir dela, uma outra proposição. Outrossim, parece que, no caso de uma sentença como (1), é a proposição enriquecida (a saber, “Eu já tomei café da manhã hoje”) que serve de input para a elaboração de algumas implicaturas (p. ex. "Não estou com fome agora"). Isso é mais um indício para suspeitar que esse constituinte acrescido ao significado literal da sentença se incorpora ao que é dito.

\section{A modulação}

Se esses traços que chamei, com certa vagueza até aqui, de "enriquecimentos", "aspectos não-articulados", "acréscimos" e de "ajustes de sentido" não podem ser nem implicaturas nem saturações (já que não 
são necessários para que as sentenças expressem proposições completas), o que eles são? Parece que estamos diante de um fenômeno completamente novo, que não se enquadra em nenhuma das classificações anteriores dos processos de influência do contexto na significação. Antes de dar nome a esse novo membro do rebanho, talvez seja proveitoso elencar suas características distintivas, com base no que pudemos deduzir dos exemplos (1)-(4):

(i) O contexto (linguístico ou extralinguístico) contribui com algum elemento à interpretação do enunciado. Trata-se, portanto de um processo pragmático. ${ }^{10}$

(ii) Essa contribuição do contexto é verocondicionalmente relevante, isto é, ela afeta o que é dito, a proposição expressada pelo enunciado. Trata-se, portanto, de um processo pragmático primário, que atua antes da derivação das implicaturas.

(iii) No entanto, tal contribuição do contexto não é necessária para que o enunciado expresse uma proposição. Ou seja, se o elemento contribuído pelo contexto fosse deixado de lado, o enunciado continuaria a expressar uma proposição completa. Trata-se, portanto, de um processo pragmático primário opcional, ao contrário da saturação, que é um processo pragmático primário obrigatório (porque atua somente quando há uma espécie de lacuna no sentido literal da sentença).

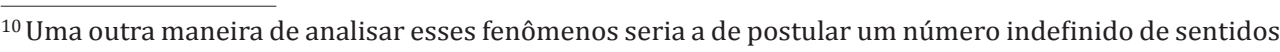
para cada uma das expressões cujas interpretações estão sujeitas a essa variação contextual. 0 papel do contexto, nos exemplos (1)-(4) seria, assim, um de desambiguação. Essa alternativa, além de ser desaconselhada pela Navalha de Ockham Modificada, não parece ser empiricamente plausível, como argumenta Recanati: "Para haver [esse] tipo de desambiguação [...] precisaria estar dada [para cada uma das expressões ajustadas] uma lista pré-estabelecida de sentidos, a partir da qual o sentido una das exente relevante seria selecionado" $(2004$, p.134) Segundo o filósofo francês, esses ajustes contextuais do sentido parecem ser muito mais o produto de um processo on “geracão" ou de "criac̃ão"

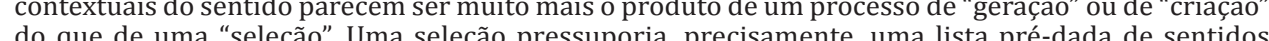
do que de " "seço".

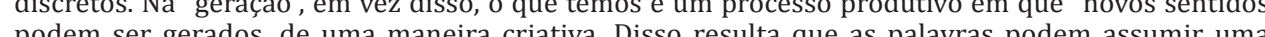
variedade infinida de sentidos possiveis." (p. 134).
}

(iv) O processo pragmático primário opcional atua localmente modificando o sentido de alguma expressão ou constituinte da sentença. Ou seja, esse processo não pressupõe a identificação prévia de uma proposição completa para depois suplementá-la com os ajustes adequados (cf. RECANATI, 2004; 2010) e CARSTON, 2002). ${ }^{11}$

São essas quatro características que definem o processo que Recanati (2004; 2010; 2014) chama de modulação. A modulação é definida como uma função pragmaticamente selecionada que toma os sentidos lexicais das expressões e constituintes como argumentos e entrega, como valor, um sentido contextualmente ajustado.

Há, de acordo com ele, três espécies principais de modulação: o enriquecimento, o afrouxamento e a transferência semântica (cf. RECANATI, 2004). No enriquecimento, o sentido que resulta da modulação é mais específico do que o sentido lexical inicial. É esse o processo que ocorre quando temos a formação dos conceitos ad hoc - como quando interpretamos, em alguns contextos, o predicado "fumar" em "João fuma" como veiculando o conceito FUMAR-MACONHA (cf. RECANATI, 2014). No afrouxamento o que acontece é precisamente o inverso. A extensão do sentido lexical da expressão modulada é, aí, expandida ao invés de restringida. Esse processo foi percebido por Austin na sua discussão sobre a verdade:

É verdadeiro ou falso que Belfast fica ao norte de Londres? Que nossa galáxia tem o formato de um ovo frito? Que Beethoven era um bêbado? Que Wellington venceu a batalha de Waterloo? Há vários graus e dimensões de sucesso quando fazemos afirmações: as afirmações se adequam aos fatos de uma maneira mais ou menos frouxa - de diferentes maneiras dependendo da ocasião e dos propósitos. (1970, p. 130)

${ }^{11}$ É essa característica que torna o contextualismo compatível com o princípio da composicionalidade linguística Nas palauras de Bezuidenhout: “[Essa] construção cragmática doconté́do atua localmente, no nível das plavras e sint Bezuidenhout. "[Essa] construção pragmática do conteúdo atua localmente, mecanismos composicinais estão prontos para an proposicionacos o nível de significado da sentença é evitado" (2009, p. 63) 
De acordo com outro exemplo célebre do filósofo inglês, o predicado geométrico "ser hexagonal" pode ter suas condições de aplicabilidade afrouxadas, em um contexto suficientemente informal, para que uma sentença como "A França é hexagonal" seja tida como verdadeira. Por fim, na transferência semântica, fenômeno descrito em detalhe por Nunberg (1995),

“o produto não é uma versão nem enriquecida nem empobrecida do conceito literalmente codificado pela expressão inicial: é um conceito diferente, que guarda alguma relação sistemática com o original" (RECANATI, 2004, p. 26). É plausível que seja isso o que sucede no seguinte exemplo citado por Recanati (2010, p. 5):

(I) Tem um leão no meio da praça.

O conceito LEÃO seria, pelo processo da transferência semântica, modulado em algo como o conceito ESTÁTUA-DE-LEÃO, dado um contexto adequado.

Para Recanati, a modulação é essencial para a comunicação humana porque "nós usamos um estoque (mais ou menos) fixo de lexemas para falar sobre uma variedade indefinida de coisas, situações e experiências." (2004, p. 131). Essa é uma das intuições fundamentais que motiva o contextualismo, desde, pelo menos, os trabalhos de Austin:

O mundo real, para as intenções e propósitos dos seres humanos, é indefinidamente variado e nós não temos a capacidade de lidar com um vocabulário indefinidamente vasto. Além disso, em geral, também não fazemos questão de insistir nas mais mínimas diferenças detectáveis entre as coisas, e sim em suas similaridades relativas. E, afinal de contas, em nossa experiência, tanto como indivíduos quanto como uma espécie, não podemos antecipar no nosso vocabulário os caprichos ainda inauditos da natureza (AUSTIN, 1970, p. 146-147).

Há, entretanto, uma objeção que é comumente levantada contra aqueles que admitem a intrusão de processos pragmáticos opcionais nas condições de verdade. ${ }^{12}$ Do mesmo modo como ambos os lados da disputa admitem que alguma influência do contexto possa ser necessária para que os enunciados expressem proposições (essa influência pode ser apenas a saturação ou pode incluir, como no caso dos contextualistas, a modulação), é ponto pacífico afirmar que um dos fatores que distinguem as condições de verdade das implicaturas é que aquelas, ao contrário destas, são, de algum modo, constrangidas pelo significado literal das expressões da sentença.

Quando o contextualista afirma que o que é dito está sujeito a profundas influências contextuais opcionais - isto é, à modulação -, ele não pretende transformar as condições de verdade em um tipo de conteúdo caótico, que pode variar indefinidamente, à maneira de Humpty Dumpty. Isso porque, de acordo com Travis,

o que as palavras significam de fato cumpre um papel na determinação das condições em que elas seriam verdadeiras, mas não um papel exaustivo. 0 significado deixa certo espaço para a variação das condições de verdade de um contexto para o outro. (1996, p. 451)

Temos, por isso, aqui, ao menos prima facie, um desafio para o contextualista: determinar como dois falantes, partindo de um mesmo significado literal esquemático, convergem em um mesmo conteúdo, ou, de algum outro modo, obtêm um razoável sucesso na comunicação, se não existe qualquer medida pré-estabelecida para o "espaço" de modulação pragmática permitida. Quais os limites da modulação?

A resposta de Recanati (2010) a esse desafio é dupla. Primeiro ele defende que esse problema - que Cappelen e Lepore (2005) apelidam de "o argumento do milagre da comunicação" - não surge apenas para o contextualista, mas para qualquer um que admita a influência de fatores

\footnotetext{
${ }^{12}$ V. Stanley $(2002 ; 2014)$
} 
contextuais amplos (ou intencionais) na comunicação, isto é, basicamente, para todo mundo. ${ }^{13}$ Quase todos os semanticistas e filósofos da linguagem de hoje admitem a necessidade de recorrer a hipóteses sobre as intenções do falante para determinar a referência dos pronomes demonstrativos, e até mesmo dos dêiticos puros como "agora" e "aqui" (pois "agora" pode se reportar tanto à hora, quanto ao dia, quanto ao ano; bem como "aqui" pode se referir a uma casa, a um bairro, a um país ou mesmo à via láctea). Isto é, mesmo os minimalistas, que admitem que o único processo pragmático primário é a saturação, são obrigados a confessar que o recurso ao contexto amplo ou intencional é necessário para a determinação das proposições, visto que isso é exigido por casos simples e óbvios de saturação, como os demonstrativos. Esse recurso, porém, sempre deixará aberta a possibilidade de incompreensões radicais.

Em seguida, Recanati observa que a constatação de que a comunicação não é - nem para o contextualista, nem para o minimalista - um milagre deve nos instigar a buscar outra explicação (i.e., uma explicação não-semântica) para o fato de que convergimos em conteúdos proposicionais suficientemente semelhantes e estáveis. A orientação que ele sugere como resposta a esse desafio é a seguinte: "essa estabilidade pode ser explicada por razões psicológicas, e não linguísticas” (RECANATI, 2004, p. 152). Falantes e ouvintes compartilham, em linhas gerais, um mesmo aparato cognitivo (cf. RECANATI, 2010), e seria esse aparato cognitivo que garantiria o sucesso da comunicação.

\section{Conclusão}

Poderíamos, para concluir essa discussão, nos perguntar exatamente o que no aparato cognitivo humano possibilita o sucesso da comunicação

${ }^{13}$ Excetuando, aí, talvez, minimalistas radicais, como Borg (2004), que temem que tais apelos possam comprometer o entendimento do processamento linguístico como uma operação modular. entre os falantes. 0 que faz com que eles confluam em direção a um mesmo conteúdo proposicional? Recanati não oferece nenhuma resposta a essas e outras questões semelhantes. Os princípios e mecanismos que guiam a modulação são, via de regra, apenas insinuados informalmente, sem qualquer justificação ou exposição explícita na sua obra. Ele diz apenas que a modulação é "guiada pelo contexto", que ocorre para tornar as condições de verdade do enunciado "adequadas" ou "relevantes" à situação em que os falantes se encontram. Em outros momentos, Recanati propõe que esquemas cognitivos e frames contextualmente salientes podem ter um papel na seleção da modulação correta (cf. RECANATI, 2004). Mas todas essas observações permanecem assistemáticas, em uma esfera fundamentalmente informal.

O principal mérito do filósofo francês foi o de ter atraído a atenção para o fenômeno da modulação, descrevendo-o e oferecendo argumentos contra aqueles que o buscavam eliminar, reduzindo-o a uma instância de saturação ou de implicatura. Não há, contudo, em Recanati, a pretensão de explicar a modulação: de elaborar, com mais vagar, a hipótese cognitiva idealizada em resposta ao argumento do milagre da comunicação. Essa parece ser, precisamente, a tarefa para algumas teorias mais próximas ao referencial do linguista, como, por exemplo, a Teoria da Relevância, proposta inicialmente por Sperber e Wilson (1995).

A tarefa que fica para o linguista diante dessas reflexões é, a meu ver, dupla. O primeiro passo é averiguar se, sob uma argumentação empírica mais rigorosa, as alegações de Recanati acerca dos exemplos linguísticos citados se sustentam. Isso presumivelmente envolverá o diálogo entre linguistas de orientação mais teórica e psicolinguistas dispostos a realizar experimentos que testem se as consequências de uma análise dos exemplos (1)-(4) em termos de modulação - e não mais de implicatura - se confirmam. É possível que processos que intervêm sobre o conteúdo proposicional (como a modulação) apresentem consequências comportamentais dife- 
rentes de processos pós-proposicionais como as implicaturas. Essas consequências podem ser discutidas e mensuradas por psicolinguistas. $\mathrm{O}$ segundo passo é, precisamente, tentar elaborar um modelo particular acerca de como informações de natureza contextual são recrutadas no processo de composição semântica. Isso envolverá a elaboração de uma hipótese a respeito das heurísticas pragmático-cognitivas envolvidas na interpretação de enunciados.

\section{Referências $^{14}$}

AUSTIN, John L. Philosophical Papers. Oxford: Oxford University Press, 1970.

BACH, Kent. Conversational Impliciture. Mind \& Language, Oxford, v. 9, n. 2, p. 124-162, 1994. http://dx.doi.org/10.1111/j.1468-0017.1994.tb00220.x

. Thought and Reference. Oxford: Clarendon Press, 1987.

BEZUIDENHOUT, Anne. Contextualism and the Role of Contextual Frames. Manuscrito, Campinas, v. 32, n. 1, p. 59-84, jan.-jun. 2009.

BORG, Emma. Minimal Semantics. New York: Oxford University Press, 2004.

CAPPELEN, Herman; LEPORE, Ernie. Insensitive Semantics: A Defense of Semantic Minimalism and Speech Act Pluralism. Malden: Blackwell Publishing, 2005. http://dx.doi. org/10.1002/9780470755792

CARSTON, Robyn. Explicature and Semantics. Disponível em: <http://www.phon.ucl. ac.uk/home/robyn/pdf/explicaturesem.pdf>. Acesso em: 31 ago. 2014.

Implicature, Explicature and Truth-Theoretic Semantics. In: DAVIS, Steven (Ed.). Pragmatics: a reader. New York: Oxford University Press, 1991.

Thoughts and Utterances: The Pragmatics of Explicit Communication. Malden: Blackwell Publishing, 2002.

COHEN, Jonathan. Some remarks on Grice's views about the logical particles of natural language. In: BAR-HILLEL (Ed.). Pragmatics of Natural Languages. Dordrecht: Reidel, 1971.

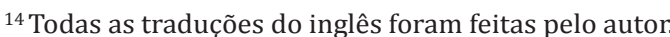

DUCROT, Oswald. O Dizer e o Dito. Campinas: Pontes, 1987.

GRICE, Paul. Presupposition and Conversational Implicature. In: COLE, Peter. Radical Pragmatics. New York: Academic Press, 1981.

Studies in the Way of Words. Cambridge: Harvard University Press, 1989.

JACKENDOFF, Ray. The Architecture of the Language Faculty. Cambridge: MIT Press, 1997

LEVINSON, Stephen. Pragmatics. New York: Cambridge University Press, 1983. MORTARI, Cezar. Introdução à lógica. São Paulo: Editora UNESP, 2001.

MOURA, Heronides; VARASCHIN, Giuseppe F. C. O Significado em Quine e Searle. Calidoscópio, São Leopoldo, v. 11, n. 3, p. 320-327, 2013.

NUNBERG, Geoffrey. Transfers of Meaning. Journal of Semantics, Oxford, v. 12, n. 2, p. 109-132, 1995. http://dx.doi.org/10.1093/jos/12.2.109

PUSTEJOVSKY, James. The Generative Lexicon. Cambridge: MIT Press, 1995.

RECANATI, François. Contextualism and anti-contextualism in the philosophy of language. In: Tsohatzsidis, Savas (Ed.). Foundations of Speech Act Theory. London: Routledge, 1994

Literal Meaning. New York: Cambridge University Press, 2004.

Pragmatic Enrichment. Disponível em: <http://jeannicod.ccsd.cnrs.fr/docs/00/ 50/39/59/PDF/Pragmatic_enrichmentFINAL.pdf>. Acesso em: 13 set. 2014.

Pragmatics and Semantics. In: HORN, L. R.; WARD, G. (Ed.). The Handbook of Pragmatics. Oxford: Blackwell, 2006. http://dx.doi.org/10.1002/9780470756959

. The Pragmatics of What Is Said. In: DAVIS, Steven (Ed.). Pragmatics: a reader. New York: Oxford University Press, 1991.

Truth-conditional pragmatics. New York: Oxford University Press, 2010.

Unarticulated Constituents, Linguistics and Philosophy, New York, v. 25, n. 3 p. 299-345, 2002. http://dx.doi.org/10.1023/A:1015267930510

RUSSELL, Bertrand. On Denoting, Mind, Oxford, v. 14, n. 56, p. 479-493, 1905.

SOAMES, Scott. Incomplete Definite Descriptions. Notre Dame Journal of Formal Logic, Notre Dame, v. 27, n. 3, p. 349-375, 1986. http://dx.doi.org/10.1305/ndjfl/1093636680

SPERBER, Dan; WILSON, Deirdre. Relevance: Communication and Cognition. Cambridge: Blackwell, 1995. 
STANLEY, Jason. Making it Articulated. Mind \& Language, Oxford, v. 17, n. 1-2, p. 149-168, 2002.

Review of François Recanati's Literal Meaning. Notre Dame Philosophical Reviews. Disponível em: <https://ndpr.nd.edu/news/24857-literal-meaning/> Acesso em: 31 ago. 2014.

STANLEY, Jason; SZABO, Zoltán. Quantifier Domain Restriction. Mind \& Language, Oxford, v. 15, n. 2-3, p. 219-261, 2000.

STRAWSON, Peter. Introduction to Logical Theory. New York: Routledge, 2011.

TRAVIS, Charles. Meaning's Role in Truth. Mind, Oxford, v. 105, n. 419, p. 451-466, 1996. http://dx.doi.org/10.1093/mind/105.419.451

Recebido em 07/10/2015.

Aceito em 06/02/2016. 